\title{
VIRIATO. UM COTEJO ENTRE AS FONTES GLÁSSICAS E A HISTORIA GENERAL DE ESPANA
}

\author{
Maria Martha Pimentel de Mello \\ Fundação Casa de José Américo - PB
}

Resumo: Juan de Mariana, autor da Histori General de Espafía, revela-se profundo conhecedor dos autores clássicos. Utiliza as fontes comparando-as entre si e seguindo a que Ihe parece melhor para cada cașo específico. Quando não está de acordo, expõe seu pensamento, destacando os motivos de sua discórdia com alguns autores. 0 grande poder de síntese que revela através de sua narrativa segue paralelo a uma sistemática ordem cronológica, somente alterada quando considera necessária a uma me/hor compreensão dos acontecimentos. Sua proposta é diferente da seguida por seus antecessores, na determinação de escrever uma história geral inovadora para sua época.

Palavans-Chaves: História Antiga; Fontes clássicas; Península Ibérica; Viriato; Guerra.

Juan de Mariana ${ }^{1}$, historiador espanhol, nascido em Talavera de la Reina em 1536, faleceu em Toledo no ano de 1624. Foi membro da Companhia de Jesus, sendo sua época marcada por grandes transformaçōes, quando o Humanismo e 0 Renascimento assistiam à difusão de suas idéias por toda a Europa. A Espanha vivia um de seus momentos de maior grandeza e os conquistadores espanhóis deslocavam a linha fronteiriça, ampliando o poderio espanhol do Novo Mundo. A religiosidade hispânica vivia momento de grande esplendor, havendo uma identificação entre os princíplos nacionais e os princípios universais do Cristianismo. Mariana é testemunha excepcional dessa época convulsa, participando em profundidade (não foi em vão que permaneceu fora da Espanha durante treze anos) dos conflitos ideológicos que dividiam a Europa. Sua obra, a História General de Espafía, publicada pela primeira vez em latim em 1592, e logo em castelhano em $1601^{2}$, é fundamental na historiografia espanhola do século XVI.

Mariana utiliza a história como mestra da vida, partindo de uma visão pragmática da mesma. São numerosas as passagens que nos levam a constatar que, para ele, o conhecimento da história deve constituir uma forma de educação, servindo para orientar a conduta individual. Com esta finalidade, não perde

1. Para as questóes gerais relacionadas com Juan de Mariana, ver Georges Cirot (Cirot, 1905); A. Pasa (Pasa, 1939); M. Ballesteros (Ballesteros Gaibrois, 1944).

2. Juan de Mariana, ao publicar sua Historia de Espafie em castelhano, atuou como autor. Não fez uma traduçăo literal da obra, mas uma adaptaçăo para os leitores de lingua castelhana, considerados culturalmente inferiores. Os eruditos liam em latim, exigindo outro nivel de explicação e necessitando também de maior profundidade nos relatos. Os objetivos das ediçð̄es em latim e castelhano eram diferentes, tendo em comum, apenas a necessidade de uma história geral do povo castelhano. 
oportunidade de fazer observações moralísticas visando a incutir nos leitores, os princípios morais que deveriam nortear suas vidas.

Entretanto no tema objeto de nosso estudo e ao falar do que motivou a guerra de Viriato, Mariana diz: " $y$ es asi comumente, que unos males vienen asidos de otros, y el fin de un desastre y daño suele ser muchas veces principio de otra mayor desgracia, y el remedio convertirse en mayor daño" (Mariana, 1852, p. 53). E, com a mesma finalidade diz mais adiante: "muchas veces se pierden los hombres por el mismo camino que pensaban remediar" (Mariana, 1852, p. 56).

Mariana pretende mostrar que a generosidade é tão válida quanto a conduta integra. Para incentivá-la segue textualmente a Valério Máximo, que ressalta o princípio moral, afirmando que "a pobreza e a avareza eram igualmente mal conselheiras de um poder demasiado livre" (Valério Máximo, 6, 4, 2).

Mariana deixa transparecer seu patriotismo em várias passagens, não perdendo oportunidade de destacar o valor dos soldados peninsulares que acossam o exército romano. Isto podemos ilustrar com a seguinte descrição: "con tanto espanto de los espanioles, que trecientos lusitanos no dudaron en trabar pelea com mil soldados romanos, en la qual mataron mas número que ellos eran. Acontecio, otrosl, que un peón espanhol puso en huida a muchos hombres de a caballo de los romanos, que espantados y atónitos, quedaban de ver que aquel hombre, de golpe mató un caballo y cortó a cercen la cabeza del que en él iba" (Mariana, 1852, p.54).

Comparando este texto com 0 escrito por 0sório sobre o mesmo assunto, somos forçados a reconhecer que Mariana recebeu uma sólida formação clássica. Quanto ao que afirma sobre o valor dos soldados espanhóis, embora conheça detalhadamente o assunto, cópia deste autor (0sório, 5, 4,3). Ao narrar as causas da guerra de Viriato ${ }^{3}$, seguindo a Suetônio (Suetônio, 1972; Galba, 3), deixa claro que foram mortos a traição. Freqüentemente emite julgamento, como podemos verificar, quando registra que "como venian descuidados, fueron todos despejados de sus armas y muertos: brava carnicerfa y deslealtad [...]. Esta crueldad de Galba..." (Mariana, 1852, p. 53). Na última parte da citação, segue a Apiano que diz: "cuando Viriato que se havia escapado de la crueldad de Galba" (Apiano, 1980; Iberia, 61).

Apesar de revelar grande patriotismo, ao narrar as façanhas dos ibéricos, não esquece de, no momento oportuno e quando the parece merecedor, enaltecer 0 valor dos romanos ou contar suas fraquezas. Agindo dessa forma, com o mesmo personagem, o consul $Q$. Cecílio Metelo exalta seu valor, e ao mesmo tempo justifica sua atitude vingativa. Sigamos textualmente a Mariana: "Varon por cierto hasta aqul de prudencia y valor aventajado, dado que por 10 que se sigue ninguna loa merece. Pero quién hay que no falte? quién hay que tenga todas sus pasiones arrendadas? Fué asi que le vino aviso como en Roma estaba nombrado para sucederlle en aquel cargo Quinto Pompeyo, de que recibio pena, que se determinó para enfraquecerlle las fuerzas, despedir a los soldados y hacer que dejasen las armas, descuidarse en la provisión de los graneros públicos, quitar

3. A luta entre béticos e lusitanos está diretamente relacionada à posse de terras férteis para a agricultura, em face da pobreza do solo lusitano. Sobre o tema ver José Maria Blázquez (Blázquez, 1974, p. 213 214) e Theodor Mommsen (Mommsen, 1983, p. 18-19). 
el sustento a los elefantes, com que murieron, otros quedaron muy flacos y sin ser de provecho: tanto puede muchas veces en los grandes ingenios la envidia y la indignación" (Mariana, 1852, p.55). Nesta última frase já transparece o Mariana moralista. Anteriormente, observamos como ele justifica o comportamento de Cecilio Metelo, exercitando o julgamento dos personagens. Assim, enfocando a causa da guerra, diz: "Esta crueldad de Galba dió ocasión para que los naturales..." (Mariana, 1852, p. 53), comportando-se como juiz, já que adjetiva Galba. Todavia, considerando o momento em que Mariana viveu, vemos que a obra insere-se no pensamento histórico de sua época. Observamos que, ao relatar os feitos de Serviliano, emite julgamento, com a preocupação de justificá-lo, quando afirma que: "Juntaba Serviliano con la diligencia que era muy grande, la severidad y el rigor.del castigo, en que era demasiado. Porque cortó las manos a todos los compañeros de Canoba y fuera de ellos a otros quinientos cautivos que faltaron en la fé y desamparon sus reales" (Mariana, 1852, p. 55). Adota a mesma postura ao tratar das negociações de paz, levadas a termo por Viriato: "Resulto que se hizo confederacion en virtud de la qual, los romanos escaparon con sus vidas, y él fué llamado amigo del pueblo romano, a sus soldados y confederados dado todo lo que tenian y habian robado. Grande ultraje y afrenta de la majestat romana [...] el consul, perdida la esperanza de haber a las manos enemigo tan astuto y tan recatado" (Mariana, 1852, p. 55).

Com o propósito de escrever uma Historia General de España, Mariana tem sempre presente 0 espirito de síntese, necessário a uma obra de tal porte. Assim, quando trata da guerra, após formular um princípio moral, passa imediatamente a descrever o caráter de Viriato. De forma bastante simplificada, e em poucas palavras, consegue transmitir uma imagem clara do herói lusitano ${ }^{4}$. Apresenta-o da seguinte forma: "Fué Viriato de nación Iuzitana, hombre de bajo suelo y linage, y que en su mocedad se ejercitó en ser pastor de ganados. En la guerra fué diestro, a la cual dió principio siendo salteador de caminos con un escuadron de gente de su mismo talle" (Mariana, 1852, p. 53). As informações sobre a pessoa de Viriato foram recolhidas em Orósio, Frontino e Livio, seguindo precisamente a este último (Lívio, Per. 52), quando registra que Viriato, passando primeiro de pastor a caçador, de caçador a bandoleiro, chega por fim a chefe de um exército regular, que se apodera da Lusitânia.

0 grande poder de síntese que revela através de sua narrativa, segue paralelo a uma sistemática ordem cronologica. Assim, após descrever Viriato e os que the seguem, narra os principais acontecimentos da guerra, distribuidos por consulado. Para cada período consular, enumera os dois cônsules e suas respectivas jurisdições, nas duas Hispanias. Cada consulado está datado segundo a fundação de Roma, e sempre Mariana assinala quando um consul é substituído e 0 outro permanece no desempenho de suas funçōes. Esta ordem deixa de ser observada, somente quando a descrição se translada a uma outra região. Sobrepõe,

4. Viriato, segundo Joăo Ameal (Ameal, 1968, p. 10) é a alma Indômita de resistencia lusitana, destacando sua rude e heróica figura, objeto de relatos extraordinários. Para Mommsen (Mommsen, 1983, p. 20), Viriato significou, entre os lusitanos, o mesmo que Ulisses, nos poemas homéricos. Segundo Javier Arce (Blázquez, 1974, p. 94), ao falar sobre a origem provavelmente humilde de Viriato, cita a opinião discordante de H. G. Gundel que justifica sua dúvida, baseado no principio de que os autores antigos ressaltavam a ascensão social dos heróis para ampliar suas glórias. 
então o regional ao cronológico. Todavia, isto não vem em detrimento do valor de sua história, ao contrário, quando assim precede, visa a inserir o fato regional no contexto geral. Procura ser minucioso, inclusive com as formalidades, quando diz: "el año que se conto 609 de la fundación de Roma, Q. Fabio Máximo Emiliano, hermano de Scipion, hecho Consul, vino en España contra Viriato por orden del senado, que cuidadoso de aquella guerra mando que el uno de los Consules partiese para España" (Mariana, 1852, p.54).

Sabe marcar a personalidade dos indivíduos, destacando 0 valor pessoal ${ }^{5}$ e deixando transparecer o poder carismático ${ }^{6}$ dos heróis que descreve. Faz brotar no leitor o sentimento de simpatia por determinadas pessoas. Quando Marco Vitilio assumiu o consulado, disposto a acabar com Viriato cujos soldados acurralados em território fechado e com os ánimos abatidos, encontravam-se dispostos a entabular conversação com o consul romano, o caudilho lusitano, ao tomar conhecimento da situação, pronunciou um discurso, chamado todos a razão (Mariana, 1852, p. 53). Seguindo seu método de enfatizar os acontecimentos históricos com discursos ${ }^{7}$ compostos por frases espetaculares, ao narrar como Metelo procura enganar Viriato sobre seus planos, informa que este, ao ser interrogado por um de seus capitães sobre 0 que pretendia fazer, "respondió aquellas palabras memorables: quemaria yo mi camisa si entediese que en mis secretos tenia parte". (Mariana, 1852, p. 55): Esta frase consta em Valério Máximo, Plutarco e Fontino. Cada um deles dá uma informação diferente sobre a pessoa que interroga Metelo. Valério Máximo diz que se trata de um intimo amigo, Plutarco fala de um dos tribunos mais jovens, e Frontino deixa indeterminado, limitando-se a dizer como se perguntasse a Metelo Pio. 0 fundamental, não somente em Mariana mas também para os autores clássicos, é a resposta de Metelo, e com ela, todos estão de acordo. Mais uma vez Mariana segue a seus mestres clássicos.

Com relação ao número de soldados de cada exército, costuma interpretá-los com liberdade. No que se refere a Viriato, em duas ocasiōes, não os reproduz de acordo com os clássicos. Falando do Cônsul Quinto Fábio Serviliano, Apiano registra que este trouxe consigo mil seiscentos ginetes e Mariana não 0 segue ao afirmar que: "trajo en su compañia diez y ocho mil infantes y mil quinientos caballos de socorro" (Mariana, 1852, p.55).

Ao narrar como o mesmo consul conquistou umas praças fiéis a Viriato, alude a um rico botim ${ }^{8}$, do qual "hizo murir quinientos que eran de los mas

5. 0 autor destaca o valor pessoal do guerreiro, descrevendo batalhas ganhas pela bravura individual, mais que por táticas bélicas.

6. Sobre o poder carismático, necessário aos lideres, João Ameal destaca que Viriato "se a fortuna delxasse teria sido outro Romulo [...] reconhece-lhe estofo para fundador de um grande império do Ocidente" (Ameal, 1968, p. 10). Referindo-se a Viriato, Mommsen ressalta seus exemplos de moderação e constância, assim como sua coragem, sempre lutando à frente das tropas, nas posições mais perigosas.

7 Os discursos exaltando os guerreiros, precedem as batalhas, com a finalidade de aguçar a bravura dos soldados. Mariana segue o exemplo de Livio e Polibio.

8. A distribuição do botim de guerra, tinha, entre outras finalidades a de despertar maior interesse $e$ bravura entre os guerreiros, pelos bens materiais que obteriam após uma vitória. Segundo Mommsen (Mommsen, 1983, p. 20), Viriato primava pela distribuição equitativa dos espólios das batalhas, nunca beneficiando-se mais que seus companheiros. 
culpables. Los demas, en número de diez mil hizo vender en pública almoneda por esclavos" (Mariana, 1852, p. 55). Apiano nos diz que "de diez mil cautivos que hizo, mandó decapitar quinientos y vendio a todos los demas" (Apiano, 1980; Iberia, 67-69).

Uma das preocupações de Mariana diz respeito à genealogia ${ }^{9}$ e aos cognomes. Como exemplo, citamos o que diz sobre o consulado de Públio Cornélio Cipião, destacando que era uma pessoa predestinada, "al cual el cielo guardaba la gloria de destruir Cartago la Grande, como lo hizo por este mismo tiempo, de donde fué llamado Africano, sobrenome que pudo heredar de su abuelo. Consta asimismo que $C$. Lelio, aquel que en Roma tuvo sobrenome de sabio, como testifico Cicerón" (Mariana, 1852, p. 54). Mariana segue os autores clássicos reproduzindo as informações neles contidas. Não podemos negar que, a seu modo, preocupa-se com a crítica documental, procurando detectar a verdade para elucidar o que não the parece claro. Assim, ao citar Plínio, diz que "con esto enviaron al Pretor Popilio. De el refiere Plínio que Viriato le entregó las ciudades que en su poder tenia, lo cual si fué verdad, debio maltratalle en alguna batalla y ponelle en gran aprieto" (Mariana, 1852, p. 55).

Ao enfocar 0 tratado de paz ${ }^{10}$, firmado entre Viriato e 0 consul Serviliano, alude a não observação do mesmo por parte dos romanos, pondo em dúvida o texto de Apiano ao dizer: "Por donde no parece llegado a razon ni cosa probable 10 que refiere Apiano, que el dicho concierto fué en Roma, aprobado por el Senado y el pueblo Romano" (Mariana, 1852, p. 55). Com relação à morte do Pretor Vetilio, Mariana diz que morreu na emboscada armada para os romanos em sua fuga para Tribola, e nisto seguiu a Apiano: "Vetílio fué también apresado y viendo viejo y obeso, 10 mató como de ningún precio" (Apiano, 1980; Iberia, 61$63)$.

0 historiador espanhol, prossegue desenvolvendo, a seu modo, a crítica documental, como podemos comprovar, com o relato de que "tuvo el consulado junto con Fábio Emiliano otro hombre principal Ilamado Lucio Hostilio Mancino, del cual se podia creer que vino también a España, y en ella venció a los gallegos si las inscripciones de Anconitano tuviesen bastante auctoridad para fiarse de lo que relatan en este caso. Otros podran juzgar el credito que se debe dar a este autor: a la verdad, por algunos hombres doctos, es tenido por excelente maestro de fabulas, y por inventor de mentiras mal forjadas" (Mariana, 1852; p. 54).

Inseriu em sua obra um grande número de inscrições que sempre estão bem colocadas como documento epigráfico e que foram recolhidas na Corónica

9. A preocupação de demonstrar uma origem nobre para determinados personagens históricos, podemos atribuifla a formaçăo clássica e ao fato de que seu modelo é calcado nesses autores, procedimento este usado frequentemente, desde Homero, sendo desnecessário citar passagens ilustrativas.

10. 0 tratado de paz entre Viriato e Serviliano resultou da vitória do lusitano sobre as tropas romanas quando, através de hábil manobra, isolou parte do exército inimigo. Ao lograr tal vitória; em vez de praticar a matança dos soldados aprisionados, devolveu-os ạo general romano. Foi então assinado um tratado de paz, seguido da concessāo, pelo senado romano, do título de Amicus Popilis Romanus, a Viriato. Sobre o tema ver J. M. Blázquez (Blázquez, 1974, p. 96) e João Ameal (Ameal, 1968, p. 11). 
General de España, de Florian de Ocampo ${ }^{11}$, e nestes casos especificos que se referem a Viriato, na continuação desta obra realizada por Ambrosio de Morales ${ }^{12}$.

Um outro ponto que poderia ser discutido, diz respeito a origem de Viriato. Seria mesmo humilde? H. G. Gundel ${ }^{13}$, põe em dúvida isto, alegando 0 costume dos autores antigos de apresentarem os heróis como pessoas de condição social modesta, para enfatizar a rápida ascensão do indivíduo, desde 0 anonimato até assumir a liderança de um grupo, tendo por único mérito seu valor pessoal. $E$, sobre o caráter de Viriato retratado por Mariana, seria ele realmente um homem tão sensato que pedia sempre o justo? Nosso autor apresenta um Viriato que conduz a homens simples, desejosos de terras férteis que thes proporcionem o sustento ${ }^{14}$. Aqui deixa transparecer a idéia que posteriormente norteará sua obra De Rege et Regis Institutione ${ }^{15}$. A técnica militar da emboscada, desenvolvida por Viriato com verdadeira arte, é revelada tanto pelas fontes como por Mariana.

Concluindo, podemos dizer que Mariana revela-se grande conhecedor dos autores clássicos. Utiliza as fontes, comparando-as e seguindo a que the parece melhor em cada caso. Quando não está de acordo, expressa seu pensamento, discordando delas. Enfatiza os princípios morais em vigência na época, procurando orientar uma conduta íntegra, no que concerne ao comportamento moral e social de qualquer grupo. Muitos destes princípios copia-os das fontes clássicas e outros são idealizados por esse historiador, com a intenção premeditada de. pautar a conduta individual.

Na obra de Mariana observamos discrepâncias com as fontes clássicas, em relação aos detalhes, como no caso da pessoa que interrogou a Metelo sobre 0 número de soldados que acompanhavam determinado general. Contudo, ressaltamos que essas diferenças ocorrem em coisas sem importância e quando as fontes clássicas não concordam entre si. Por outro lado constatamos que está presente, tanto em Mariana como nos autores clássicos, um total repúdio ao assassinato de Viriato ${ }^{16}$, não somente no tocante aos assassinos, mas também

11. Florian de Ocamplo nasceu em Zamora entre 1490 e 1495, falecendo em Cordoba em 1558. E autor da Corónica General de España, abordando desde as origens à morte dos Cipions, revela a preocupação de glorificar o passado espanhol.

12. Ambrósio de Morales, continuou a obra de Florian de Ocampo após sua morte. Para maior informação sobre este autor, ver E. Redel (Redel, 1908).

13. Sobre o tema ver H. G. Gundel (Gundel, 1968).

14 . J. M. Blázquez (Blázquez, 1974, p. 212) diz que segundo J. Caro Baroja, o banditismo lusitano resultou da desigualdade social entre os latifundiários e os que nada possuiam. Não se tratava de movimento organizado como os do norte, nem organização citadina como a do sul. A gerrilha surgiu pela carência de condiçōes de sobrevivência.

15. Mariana escreveu o livro De Rege of Regis Intitutione, primeiramente em latim, em 1599. Nele, 0 autor expressa que a terra deve ser aproveitada adequadamente, embora tenha sido a justificação do tiranicídio, 0 que tornou a obra famosa e que deu lugar a que fora, posteriormente, queimada e seu autor perseguido e preso.

16. Sobre a morte de Viriato, esta foi decidida em Roma. Com esta finalidade foi para a Hispania, quinto Servilio Cipião, filho de Paulo Emlilo Cipião, com instruçōes de matar Viriato. Conseguiu que os próprios emissários lusitanos 0 assassinassem. Com o fim do lider, os guerreiros perderam o espírito combativo, propiciando pouco depois, 0 final de guerra. Ver Manuel Ballesteros Gaibrois (Ballesteros Gaibrois, 1967, p. 169). 
com relação ao general Sertório que em Roma, por este motivo deixou de receber a homenagem do triunfo.

0 que falta na obra histórica de Mariana é o enfoque social e econômico. Sua obra é mais uma história militar onde enfatiza, com descrição minuciosa, as técnicas usadas nas batalhas, segundo o modelo clássico. Também encontram-se ausentes comentários sobre os costumes e sobretudo omite as aspirações do povo.

Para terminar, podemos apreciar o valor de Viriato através do epitáfio que Ihe foi dado por Mariana, e que pode servir como paråmetro sobre o caráter do caudilho lusitano: "Perecio por engaño y maldad de los suyos el libertador se puede decir de España, y que no acometio los principios del poder romano como otros, sino la grandeza y la majestad de su imperio, cuando florescian sus armas, y a un no reinaban los vicios que al fin los derribaron" (Mariana, 1852, $\mathrm{p}$. 56).

ABstract: Juan de Mariana, the author of Historia General de Espafia appears as a profound expert on classical writers. When using the historical sources, he makes comparisons among them and after a careful analysis he takes the one which seems the best for each specific case. When he does not agree wich the source, he explains his thought and emphasizes the context. The great power of synthesis detected throughout his narrative follows concurrently a systematic chronological order, when is necessary a better comprehension of events. His proposal is contrany to the regional. features with a firm wish to write a general history, innovative to his time.

Bibliografia

\section{TEXTO}

MARIANA, J. Historia General de España. Madrid: Oficinas y Estabelecimento Tipográfico del Semanario Pintoresco Español y de la llustración, 1852.

\section{FONTES CLA\$SICAS}

APIANO. Historia Romana. Tradução de Antonio Sancho Royo. Madrid: Gráficas Condor, 1980.

SCHULTEN, A. o outros. Fontes Hispaniae Antiquae. Las guerras de 154 a 72 a. de J. C. Fasciculo IV. Barcelona: Libreria Bosch, 1937.

SUETONIO. Los doce Césares. Tradução de Jaime Arnal. Barcelona: Gráficas Diamante, 1972. 


\section{Obras Especializadas}

AMEAL, J. História de Portugal. Porto: Tavares Martins, 1968.

BALleSTEROS GRAibrols, M. El Padre Juan de Mariana. La vida de un sabio. Barcelona: Amaltea, 1944.

Ballesteros Graibrols, M. Juan de Mariana. Pensador e polltico.Madrid: Ed. Fé, 1944.

BALLESTEROS GRAIBROIS, M. Historia de España. Barcelona: Surco, 1967.

BlazQUEZ, J. M. Ciclos y Temas de la Historia de España: La romanización. Madrid: Istmo, 1974.

BLAZqUEZ, J. M. e outros. Historia de España Antiqua. Hispania Romana. Tomo II. Madrid: Cátedra, 1978.

CIROT, G. Etudes sur I'historiographie espagnole. Mariana Historien. Bordeaus: Feret \& Fils Editeur, 1905.

FERREIRA, J. Historia de Portugal. Porto: Domingos Barreira, s/d.

GUNDEL, H. G. Viriato. Lusitano, cauditlo en las luchas contra los romanos. 147139 a. C. Caesaraugusta, 1968.

MELlo, M. M. P. La Historia Antiga en Juan de Mariana. Tese doutoral. Servilha, 1981.

MOMMSEN, T. Historia de Roma. Volume V. Tradução de A. Garcia Moreno. Madrid: Turner, 1983.

OCAMPO, F. Corónica General de España. Continuador da obra de Ambrósio de Morales. Madrid: Oficina de Don Benito Cano, 1791.

PASA, A. Un grande teórico della política nella Spagna del secolo XVI: il gesuita Giovani Mariana. Napoles: Rondinella, 1939.

REDEL, E. Ambrosio de Morales. Estudio Bibliográfico. Córdoba: Imprensa del Diario, 1908. 